\title{
Evaluation of current methods to detect the mutations of epidermal growth factor receptor in non-small cell lung cancer patients
}

\author{
Jasmina Obradovic ${ }^{1}$ and Vladimir Jurisic ${ }^{2 *}$
}

\begin{abstract}
Many different methods were developed to detect commonly known mutations and to screen new mutations of the epidermal growth factor receptor in non-small cell lung cancer patients. Some of these methods are so sensitive as to be able to detect even one epidermal growth factor receptor mutant tumor cell among up to 10002000 normal cells. We have considered current methods chronologically reported to detect mutations in epidermal growth factor receptor in patients with non-small cell lung cancer. We also gave a short preview of their significance for routine clinical works. A Pub Med literature search was performed in order to demonstrate what methods are mostly used in mutation detection and to show their distribution through the last 10 years.
\end{abstract}

Keywords: EGFR, Methods, Mutations, NSCLC

\section{Review}

Introduction

An extensive genetic research has provided a lot of useful information about molecular genetic abnormalities, including chromosomal aberrations, over-expression of oncogenes, and deletions or mutations in tumor suppressor genes. These results have been applied to early detection, classification, and prognosis of NSCLC [1].

Epidermal growth factor receptor (EGFR) is a transmembrane receptor protein with a ligand-binding extracellular domain, trans-membrane domain, and cytoplasmic tyrosine kinase (TK) domain. EGFR is a member of a family of four tyrosine kinase receptor (RTK) molecules. Several ligands bind with receptor(s) and activate them inducing autophosporilation of TK domain, which is usually affected with mutations. This leads to a series of intracellular signaling pathways, which in turn result in cancer proliferation, reduced apoptosis, invasion, metastasis, and stimulation of tumor-induced angiogenesis [1].

\footnotetext{
*Correspondence: vdvd@mailcity.com

${ }^{2}$ Faculty of Medicine, University of Kragujevac, Svetozara Markovica 69, 34 000, Kragujevac, Serbia

Full list of author information is available at the end of the article
}

Non-small cell lung cancer (NSCLC) is the most common cause of cancer-related death in the world [2]. EGFR is over-expressed in several tumor types, including NSCLC, and it was one of the molecules that were recognized as a biomarker for the development of targeted therapies [3,4]. The deletion of the four amino acid sequence (del 746-750) in the exon 19 and the substitution of leucine by arginine at codon 858 (L858R) in exon 21 are two of the most common mutations in the kinase domain of EGFR gene in NSCLC patients [5].

The small-molecule tyrosine kinase inhibitors including gefitinib and erlotinib have recently been approved for the treatment of patients with NSCLC [4,6-9]. In addition, mutations in the epidermal growth factor receptor (EGFR) have been confirmed as predictors of the efficacy of treatment with EGFR-tyrosine kinase inhibitors. The results from several randomized phase III trials have emphasized the importance of molecular testing prior to initiating first-line therapy for advanced NSCLC. Increasing evidence demonstrates that patients with EGFR mutations experience a more significant benefit with gefitinib or erlotinib compared to standard chemotherapy, whereas an opposite effect occurred in patients with EGFR-mutation negative tumors [7-9].

We have considered several methods to detect EGFR mutation reported in literature and come into use in the

\section{Biomed Central}


last decade. In addition we have analyzed a variety of sophisticated novel methods and previewed their significance for routine laboratory and clinical work.

\section{Data review and interpretation}

Pub Med literature was reviewed in May and April 2012 for all studies published from Jan 1, 2000 to December 31, 2011. In this search we took next key words: "mutations", "epidermal growth factor receptor", "EGFR", "non-small cell lung cancer", "NSCLC", actually "mutations epidermal growth factor receptor EGFR non-small cell lung cancer NSCLC" in single search, with activated limits that included "Humans", "Cancer" and "Publication Date". We thus obtained 1,270 articles. Articles included in our analysis are presented in Figure 1.

We excluded reviews, reports (clinical trials, and case reports), guidelines, editorials (editorial letters, news, correspondences etc.), reports that were not in English language or were not available, those which mismatched our search terms (articles that discussed about other proteins of mentioned signal pathways, not about EGFR, or about other diseases) and articles published in 2012 (Figure 1).

\section{Overview of current methods for detection mutations of EGFR in NSCLC patients Immunohistochemistry}

Immunohistochemistry (IHC) is based on the binding of antibodies tagged with a visible label to the specific antigens in tissue sections [10]. Immunohistochemical analyses are routinely performed in clinical laboratories and they can simultaneously analyze expression level of proteins or protein modifications. The advantage of this technique for a wide use in clinical practice is the possibility to preserve tumor morphology [11]. Immunohistochemical method with monoclonal antibodies is much easier and more cost-effective than analysis of extracted DNA [12].

\section{FISH assay (fluorescence in situ hybridization)}

This is a method for detection of number of copies of specific genes and location of the target sequences by fluorescent label probe [13]. The main barriers to routinely performing FISH in clinical laboratories include lack of availability in molecular techniques and of experience with the equipment for the dark-field fluorescence microscopy that is needed to assess copy number $[11,14]$.

One alternative to FISH might be chromogenic in situ hybridization (CISH), which uses bright-field light microscopic techniques to assess gene copy number and seems to be accurate and reproducible at the same time $[11,15]$.

\section{High-performance liquid chromatography (HPLC)}

Denaturing high performance liquid chromatography (DHPLC) is another method to detect somatic and inherited mutations [16]. NSCLC specimens were analyzed by high performance liquid chromatography on the Transgenomic WAVE HS system by Jänne [17]. It is a rapid method for EGFR mutation screening with $100 \%$ sensitivity and without false negatives. It could detect clinically relevant mutations in small diagnostic specimens. Mutations in exons 18 to 21 of EGFR were analyzed using a DNA endonuclease, SURVEYOR, which

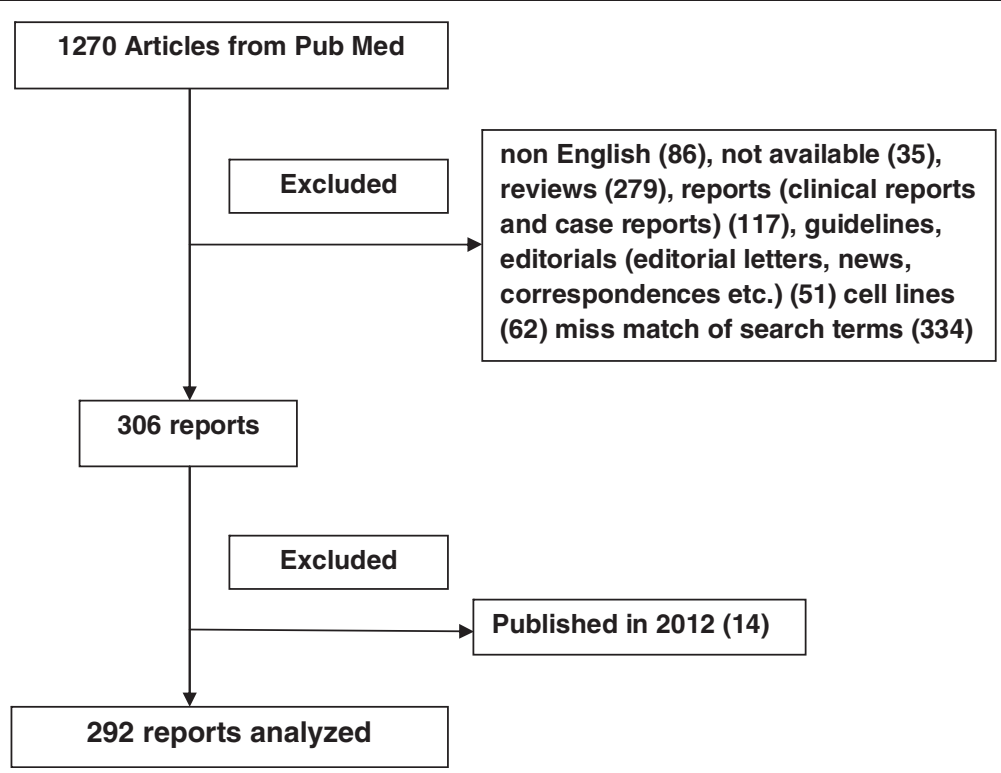

Figure 1 Diagram of included and excluded articles (292 articles were chosen for analysis). 
cleaved mismatched heteroduplexed DNA. For these analyses DNA could be prepared from both frozen and formalin-fixed, paraffin-embedded (FFPE) tumor specimens, without micro or gross dissection. This scanning technique is superior to direct sequencing when used with undissected formalin-fixed, paraffin-embedded specimens. Seven out of 160 (4\%) mutations not previously detected by direct sequencing could be detected using SURVEYOR [17].

Cohen found advantages of DHPLC [18], like detection of mutations in exons 19 and 21, without resorting to the digestion step described in the Jänne et al., which makes this method less costly. Genotyping with this technique can be done very rapidly. However, homozygous mutation would miss this method and DHPLC lacks the capacity to predict the exact nature of the mutation. Therefore, subsequent verification by direct sequencing would still be needed to identify the mutation in positive cases [18].

Tan Min Chin developed a partially denaturing HPLC (pDHPLC) assay [19] to detect a large range of sequence variants with high sensitivity and low detection limits for minority alleles in an inexpensive and standardized manner. It is suggested as a useful approach for routine detection of EGFR variants [19].

\section{DNA sequencing}

One of the sequencing methods, known as direct DNA sequencing, is based on DNA synthesis in vitro having four precursor nucleotides (NTP's) and four deoxynucleotides (ddNTP's), one of which is often labeled in four polymerase reactions [20]. It has now been developed an automated sequencing and reactions are performed in a single tube containing all four ddNTP's, each labeled with a different color dye [21,22]. Also there are novel methods of sequencing like pyrosequencing [23,24], hybridization sequencing [25], and sequencing by denaturation [26].

Direct DNA sequencing of PCR-amplified genomic DNA has been developed to detect EGFR mutations in patient's tumor tissue. Sensitivity of DNA sequencing is affected with some steps. Biopsy treatment usually provides small amount of tissue, which is often not enough amount of DNA for extraction from tumor samples. Paraffinisation of tissues after biopsies is another step where DNA could be lost, or it is a poor-quality for DNA sequencing regarding cross-contamination with DNA from stromal cells. The quality of this method is affected by the percentage of tumor cells in the sample and within the mutation. Routine use of this method in clinical laboratories is still often limited by financial and technical constraints and also by length of the procedure. It requires a few days to obtain a result after tissue acquisition $[15,27]$. This method involves multiple steps (DNA extraction, PCR-based amplification, DNA sequencing, and sequence interpretation). Sensitivity of direct sequencing is suboptimal for clinical tumor samples; mutant DNA needs to comprise $\geq 25 \%$ of the total DNA to be easily detected [9].

Polymerase chain reaction The polymerase chain reaction (PCR) is a rapid method used for exponential amplification of a particular DNA sequence. PCR can be extensively modified, and has a wide range of applications $[28,29]$. We describe here some usually applied PCR techniques to diagnose EGFR mutations in NSCLC.

Reverse Transcription PCR (RT-PCR) is a method that uses RNA as a template for an enzyme, reverse transcriptase that transforms RNA into cDNA which is then amplified by regular PCR. RT-PCR is widely used to determine the expression of a gene and does not require post-PCR sample handling, preventing potential PCR product contamination and resulting in much faster and higher throughput assays [30,31].

Quantitative PCR(qPCR, also called real-time PCR) is precisely a method used to measure the quantity of a PCR product in a real-time. It is used to determine the presence of a DNA sequence in a sample and the number of its copies in the sample. This qPCR uses fluorescent dyes, such as Sybr Green, EvaGreen or fluorophorecontaining DNA probes, such as TaqMan, to measure the amount of amplified product in real time [32,33].

The mutant-enriched PCR The mutant-enriched PCR is a rapid and sensitive assay and it can detect one mutant gene among as many as $10^{3}$ to $10^{4}$ copies of the wild-type gene [34-36]. It eliminates wild-type genes selectively and enriches the mutated genes, in two-step PCR with intermittent restriction digestion [37].

This method can detect EGFR mutations in various kinds of clinical samples including specimens by biopsies, pleural fluid, and surgically resected tissues from patients with NSCLC. But this assay can only be used to analyze specific alterations containing a commonly deleted region of exon 19 (codons 747-749) and the L858R mutation of exon 21. It cannot detect minor alterations, like mutations in exon 18, minor deletions of exon 19, and exon 20 insertions [37]. False-positive result could occur within the mutant-enriched PCR caused by high PCR cycle number. It caused replacement of a critical nucleotide. Restriction site of wild-type fragments could be destroyed. Results were confirmed with the mutant-enriched PCR assay at least twice and also performed sequencing to confirm the EGFR alterations. This is an important and sensitive assay, because it can detect commonly known mutations in heterogeneous clinical samples that may contain a small fraction of mutated genes and a large amount of wild-type genes [37]. 
Several data indicated that methods of mutant-enriched PCR could be used in pleural effusion for screening EGFR mutation in inoperable advanced NSCLC patients. The results of comparing direct sequencing with mutantenriched PCR indicated that a significant portion of mutations could be missed by using direct sequencing [38].

Peptide nucleic acid-locked nucleic acid (PNA-LNA) PCR clamp PNA-LNA PCR clamp is a sensitive and rapid method that was used for simultaneous detection of 11 different EGFR mutations [39]. In addition, several authors [40] screened about 30 non-small cell lung cancer cell lines, and among these established cell lines from Japan people's, eleven showed mutations. Briefly, these results indicated that many cell lines have subpopulations that hold specific EGFR mutations [40].

When using PNA clamp primers, amplification of the wild-type sequences is suppressed, but amplification of the mutant sequences is enhanced. LNA probes specifically detect mutant sequences in the presence of wild-type sequences. Because PNA clamp primers have wild-type sequences and LNA probes have mutant sequences, they are located in the position. PNA clamp primers competitively inhibit mutant LNA probes to bind to the wild type, further increasing the specificity of detection. Thus, individual EGFR mutations can be detected in the presence of 100- to 1,000-fold wild-type EGFR background molecules. Researchers were multiplexed the reactions by using multiple probes labeled with different dyes to detect 11 mutations by five reactions. Even after being multiplexed, each mutation was detected in the presence of 100- to 1,000-fold background [40].

Double-stranded PCR product formation assay performed by Light Cycler This assay was performed by Sasaki [41] who investigate EGFR mutation status in Japanese lung cancer patients. The principle of this method is measuring fluorescence of the SYBR Green dye when it is intercalated in double-stranded DNA, during PCR reaction, so it detects double-stranded PCR product formation [41].

For the detection of mutations in very small amounts of DNA is often used "nested PCR", that is avoided by using this assay. The advantage of this method is avoiding ethidium bromide stain, which is potentially toxic reagent. Researchers developed three different PCRs to detect EGFR gene mutations and deletions. Three common EGFR mutations were analyzed, (in exon 18, a G719S mutation, deletion in exon 19 and (CTG $\rightarrow$ CGG; L858R) mutation in exon 21) by real-time quantitative PCR with mutation-specific sensor and anchor probes [41].

Although researchers have only checked the three most frequent mutations, this is a rapid method without need for any post-PCR sample manipulation, which saves time and minimizes the risks of DNA contamination. Double-stranded PCR product formation assay performed by Light Cycleris is proposed for screening and treatment evaluation, so it could be used in predicting the sensitivity or resistance to TKI therapy for lung cancer patients [41].

\section{Polymerase chain reaction single-strand confor-} mation polymorphism (PCR-SSCP) In a study performed by Marchetti [42], PCR-SSCP analysis was found to be more sensitive than direct sequencing of PCR products, allowing identification of mutations that were hardly detectable or undetectable (21\% of cases) by direct sequencing. Mutations missed by direct sequencing were all point mutations. It was examined in NSCLC patientsfor EGFR mutations in exons 18, 19, and 21 using a direct sequencing of polymerase chain reaction products and PCR-SSCP analysis. More than $90 \%$ of the mutations in the EGFR gene could be immediately recognized by SSCP analysis. No false-positive or falsenegative results were obtained using the SSCP assay. PCR-SSCP assay could be performed on formalin-fixed, paraffin-embedded small biopsies [43], allowing the detection of mutations from minimal amounts $(<1 \mu \mathrm{g})$ of starting DNA. The authors found three new mutations (two new types of deletions and a new amino acid substitution at codon 858) and confirmed the presence of several hot spot mutations [42].

\section{Frequency of current methods reported in literature for EGFR detection}

We have presented numbers of published articles and methods that were used for the set period of time (Figures 2 and 3). Immunohistochemical analyses (IHC), were not used only as single methods but very often in combination with direct sequencing (DS), and/or fluorescence in situ hybridization (FISH) and/or chromogenic in situ hybridization (CISH). Also these combinations involved peptide nucleic acid-locked nucleic acid (PNA-LNA) PCR clamp for EGFR mutation analyses. Denaturing high performance liquid chromatography (dHPLC) was analyzed with direct sequencing, or even with some additional methods like PCR, Scorpion Amplified Refractory Mutation System technology (SARMS) [44].

Search criteria that included "polymerase chain reaction" referred also to real time polymerase chain reaction (or quantitative polymerase chain reaction) as well as reverse transcription polymerase chain reaction. Among novel PCR methods there are methods like: cycleave real-time PCR [45], Scorpion Amplified Refractory Mutation System technology (SARMS) [46] or nano-fluidic digital PCR arrays [47]. As novel methods for estimation of EGFR have also been reported: 


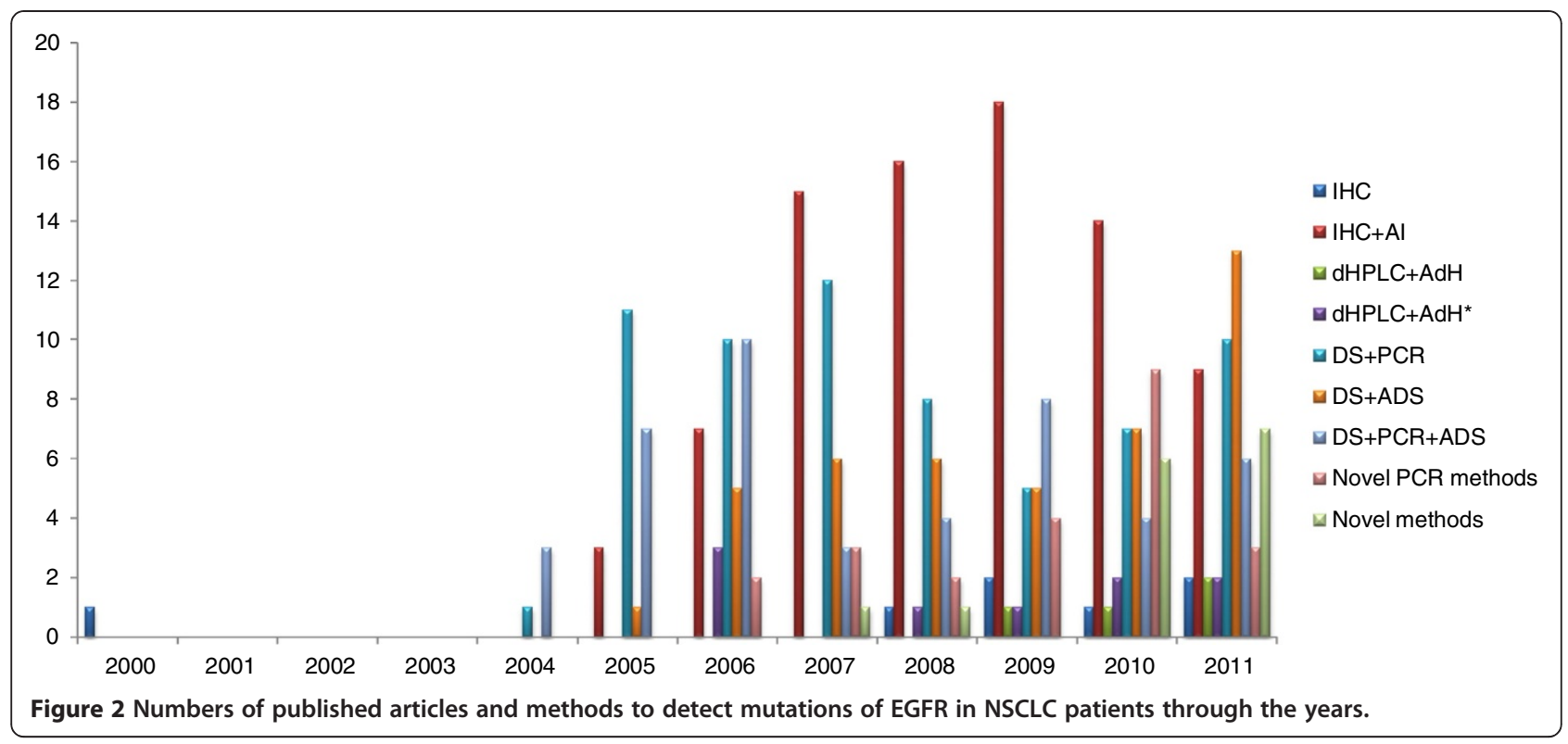

fully automated system with a nano-scale engineered biomagnetite [48], colorimetric detection of mutations in EGFR using gold nano-particle aggregation [49] or detection of the EGFR mutation in NSCLC using molecular beacons [50].
The distribution of methods used in ERGF mutation detection for the set period of time is illustrated in Figure 2. Immunohistochemical analyses in combination with PCR, direct sequencing, FISH or $\mathrm{CISH}$ were more frequently used in the period from 2001 to 2005. The

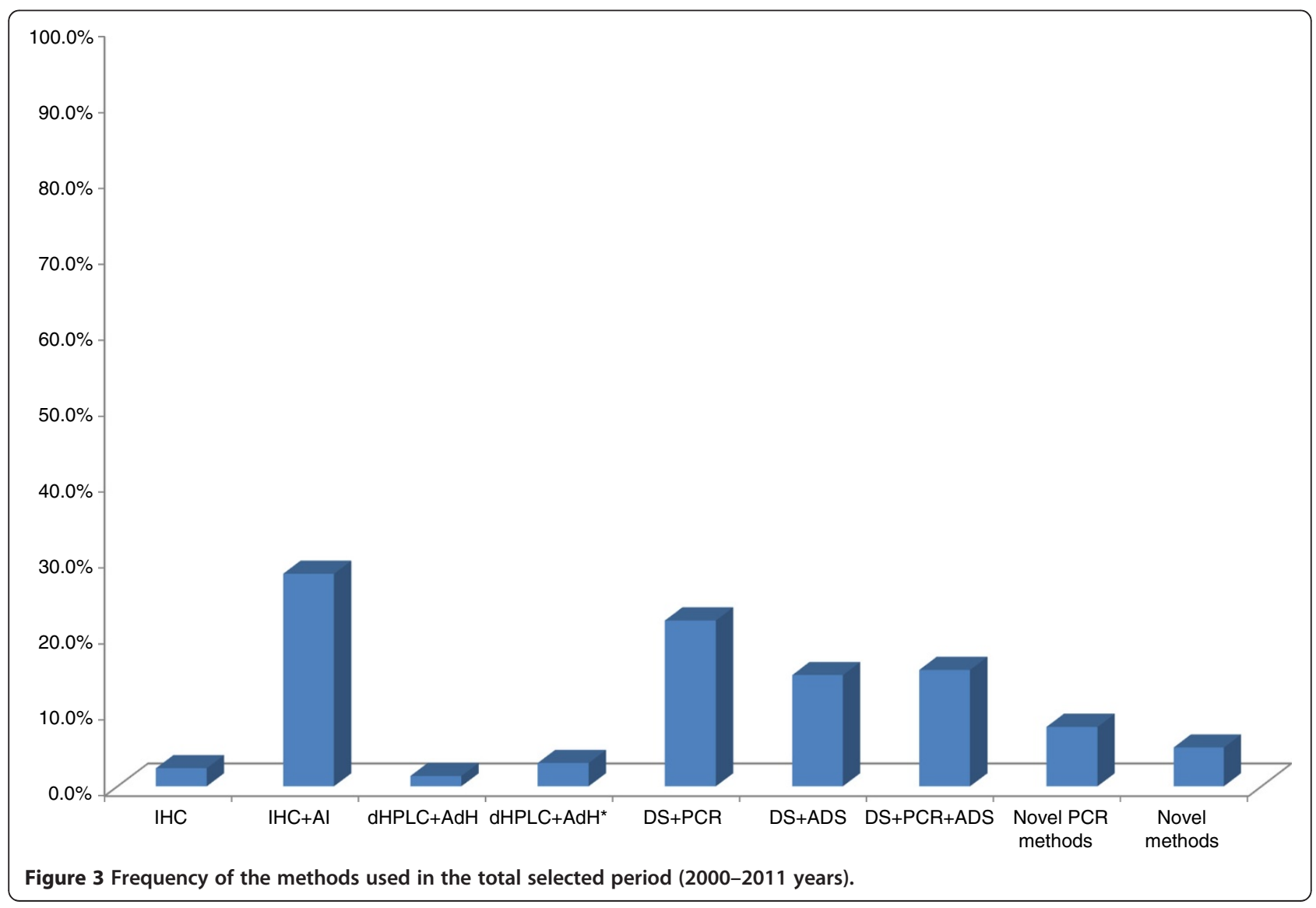


immunohistochemistry is probably mostly used in clinical practice based on the consideration that protein expression level can be evaluated directly on tumor cells or on other specific cells of interest from formalin fixed and paraffin embedded tissue. However, some subjectivism in visual description contributes to the limitation of this semiquantitative method [51]. The main lack of FISH technology is an epifluorescent system, that could be overcame with CISH which uses bright-field microscopy [51].

DNA sequencing, in the majority of the research paper confirmed data analyzed previously by any other methods. The advantage of PCR methods is that they enable the analysis of a small tissue samples, like cells from body fluids, bronchial washings, fine needle aspirates, as well as circulating tumor cells.

DHPLC is used nowadays but often with direct sequencing. This method showed higher sensitivity when compared to gene sequencing for most frequent mutations of EGFR (deletion mutation and L858R mutation). It was shown that the frequency of these mutations detected by DHPLC was $30.1 \%$, and that the analyses were technically easier and less expensive for routine clinical practice [44].

In the past six years direct sequencing, in combination with PCR alone or with PCR and other advanced techniques, has widely been used to detect EGFR mutation in NSCLC. Recently, sensitive approaches to detect mutation have been developed, including advanced PCR methods, but they are less applied. PCR methods in combination with highly sensitive methods usually need confirmation by direct sequencing, but they allow modifications and specialization, so it could be said they are almost inevitable.

There are several differences in interpreting the intensity of expression and the localization of receptors, and the wide range of methods in use for EGFR detection, that causes heterogeneity of available reports [52]. So, there is no definitive conclusion and recommendation on which are the best methods to detect the mutations of EGFR in NSCLC patients. Through the analysis of the literature we gathered some problems that might be helpful in the choice of methods to use: heterogeneity of the samples for analysis [15,37]; different types of ligands that activate EGFR, and other members of epidermal growth factor receptor family; plenty of signal downstream pathways after receptors activation [53]; development of resistance after TKIs treatment and appearance of secondary mutations [54]; undefined and unclear relation between EGFR over-expression and tumor invasiveness [55,56]; adverse effects of chemotherapy [57]; polymorphism of EGFR gene [58]. Non membrane bound events and other mechanisms of increased signaling in the modulation of specific behaviors should also be considered [52]. There are certain efforts to provide universal scoring system and standardization of techniques and this is discussed by Molecular Assays in NSCLC Working Group. They recommend EGFR molecular assays for the use and propose guidelines for tissue storage, handling, and processing [11].

\section{Conclusion}

A lot of methods are used to determine mutations of EGFR. These methods described here are highly sensitive, but usually available to detect only commonly known mutations of EGFR in NSCLC patients. DNA sequencing is widely used, but it is time-consuming and sensitivity of this method is often concerned.

We wish to point out that certain methods described here are generally used in the diagnosis of the tumor from biopsy. Other more sensitive methods are recommended to determine the presence of the mutation of EGFR from small tissue quantities. EGFR gene copy number can be assessed by a variety of methods, including FISH, CISH, and real-time quantitative PCR. Several publications reported up to $90 \%$ sensitivity for detection of EGFR mutations in circulating tumor cells isolated from patients with metastatic NSCLC $[47,48]$.

However, to detect the presence of minimal residual disease or molecular disease remission - thus solving a big problem in the clinical practice - we would suggest the need to introduce new, highly specific and more sensitive methods constantly.

\section{Abbreviations}

AdH: Additional methods to dHPLC, like DS; AdH*: Additional methods to dHPLC: one or more than one; ADS: Additional methods to DS: one or more than one; Al: Additional methods to IHC, like: and/or D.S + and/or PCR + and/ or fluorescence in situ hybridization (FISH) + and/or chromogenic in situ hybridization (CISH); dHPLC: Denaturing high performance liquid chromatography; DS: Direct DNA sequencing; IHC: Immunohistochemical analysis; PCR: Polymerase chain reaction.

\section{Competing interest}

The authors declare that they have no competing interests.

\section{Acknowledgements}

This work was supported by the Ministry of Science and Technology of the Republic of Serbia, number 175056.

\section{Author details}

${ }^{1}$ Institute of Biology and Ecology, Faculty of Science, University of Kragujevac, Radoja Domanovica 12, 34000, Kragujevac, Serbia. ${ }^{2}$ Faculty of Medicine, University of Kragujevac, Svetozara Markovica 69, 34 000, Kragujevac, Serbia.

Received: 12 September 2012 Accepted: 19 November 2012 Published: 11 December 2012

\section{References}

1. Herbst RS: Review of epidermal growth factor receptor biology. Int J Radiat Oncol Biol Phys 2004, 59:21-26.

2. Parkin DM, Bray F, Ferlay J, Pisani P: Global cancer statistics, 2002. CA Cancer J Clin 2005, 55:74-108.

3. Mendelsohn J: Antibody-mediated EGF receptor blockade as an anticancer therapy: from the laboratory to the clinic. Cancer Immunol Immunother 2003, 52:342-346. 
4. Minna JD, Peyton MJ, Gazdar AF: Gefitinib versus cetuximab in lung cancer: round one. J Natl Cancer Inst 2005, 97:1168-1169.

5. Mitsudomi T, Yatabe $Y$ : Mutations of the epidermal growth factor receptor gene and related genes as determinants of epidermal growth factor receptor tyrosine kinase inhibitors sensitivity in lung cancer. Cancer Sci 2007, 98:1817-1824.

6. Kris MG, Natale RB, Herbst RS, Lynch TJ Jr, Prager D, Belani CP, Schiller JH, Kelly K, Spiridonidis H, Sandler A, Albain KS, Cella D, Wolf MK, Averbuch SD, Ochs JJ, Kay AC: Efficacy of gefitinib, an inhibitor of the epidermal growth factor receptor tyrosine kinase, in symptomatic patients with non-small cell lung cancer: a randomized trial. JAMA 2003, 290:2149-2158.

7. Lynch TJ, Bell DW, Sordella R, Gurubhagavatula S, Okimoto RA, Brannigan BW, Harris PL, Haserlat SM, Supko JG, Haluska FG, Louis DN, Christiani DC, Settleman J, Haber DA: Activating mutations in the epidermal growth factor receptor underlying responsiveness of non-small-cell lung cancer to gefitinib. N Engl J Med 2004, 350:2129-2139.

8. Paez JG, Jänne PA, Lee JC, Tracy S, Greulich H, Gabriel S, Herman P, Kaye FJ, Lindeman N, Boggon TJ, Naoki K, Sasaki H, Fujii Y, Eck MJ, Sellers WR, Johnson BE, Meyerson M: EGFR mutations in lung cancer: correlation with clinical response to gefitinib therapy. Science 2004, 304:1497-1500.

9. Pao W, Miller V, Zakowski M, Doherty J, Politi K, Sarkaria I, Singh B, Heelan R, Rusch V, Fulton L, Mardis E, Kupfer D, Wilson R, Kris M, Varmus H: EGF receptor gene mutations are common in lung cancers from "never smokers" and are associated with sensitivity of tumors to gefitinib and erlotinib. Proc Natl Acad Sci USA 2004, 101:13306-13311.

10. Ramos-Vara JA: Technical aspects of immunohistochemistry. Vet Pathol 2005, 42:405-426.

11. Eberhard DA, Giaccone G, Johnson BE, Non-Small-Cell Lung Cancer Working Group: Biomarkers of response to epidermal growth factor receptor inhibitors in Non-Small-Cell Lung Cancer Working Group: standardization for use in the clinical trial setting. J Clin Oncol 2008, 26:983-994.

12. Yu J, Kane S, Wu J, Benedettini E, Li D, Reeves C, Innocenti G, Wetzel R, Crosby K, Becker A, Ferrante M, Cheung WC, Hong X, Chirieac LR, Sholl LM, Haack H, Smith BL, Polakiewicz RD, Tan Y, Gu TL, Loda M, Zhou X, Comb MJ: Mutation-specific antibodies for the detection of EGFR mutations in non-small-cell lung cancer. Clin Cancer Res 2009, 15:3023-3028.

13. Varella-Garcia M: Stratification of non-small cell lung cancer patients for therapy with epidermal growth factor receptor inhibitors: the EGFR fluorescence in situ hybridization assay. Diagn Pathol 2006, 1:19.

14. Hirsch FR, Varella-Garcia M, McCoy J, West H, Xavier AC, Gumerlock P, Bunn PA Jr, Franklin WA, Crowley J, Gandara DR, Southwest Oncology Group: Increased epidermal growth factor receptor gene copy number detected by fluorescence in situ hybridization associates with increased sensitivity to gefitinib in patients with bronchioloalveolar carcinoma subtypes: a Southwest Oncology Group Study. J Clin Oncol 2005, 23:6838-6845.

15. Sholl LM, John lafrate A, Chou YP, Wu MT, Goan YG, Su L, Huang YT, Christiani DC, Chirieac LR: Validation of chromogenic in situ hybridization for detection of EGFR copy number amplification in nonsmall cell lung carcinoma. Mod Pathol 2007, 20:1028-1035.

16. Liu W, Smith DI, Rechtzigel KJ, Thibodeau SN, James CD: Denaturing high performance liquid chromatography (DHPLC) used in the detection of germline and somatic mutations. Nucleic Acids Res 1998, 26:1396-1400.

17. Jänne PA, Borras AM, Kuang Y, Rogers AM, Joshi VA, Liyanage H, Lindeman N, Lee JC, Halmos B, Maher EA, Distel RJ, Meyerson M, Johnson BE: A rapid and sensitive enzymatic method for epidermal growth factor receptor mutation screening. Clin Cancer Res 2006, 12:751-758.

18. Cohen V, Agulnik JS, Jarry J, Batist G, Small D, Kreisman H, Tejada NA Miller WH Jr, Chong G: Evaluation of denaturing high-performance liquid chromatography as a rapid detection method for identification of epidermal growth factor receptor mutations in nonsmall-cell lung cancer. Cancer 2006, 107:2858-2865.

19. Chin TM, Anuar D, Soo R, Salto-Tellez M, Li WQ, Ahmad B, Lee SC, Goh BC, Kawakami K, Segal A, lacopetta B, Soong R: Detection of epidermal growth factor receptor variations by partially denaturing HPLC. Clin Chem 2007, 53:62-70.

20. Sanger F, Nicklen S, Coulson AR: DNA sequencing with chain-terminating inhibitors. Proc Natl Acad Sci USA 1977, 74:5463-5467.

21. Innis MA, Myambo KB, Gelfand DH, Brow MA: DNA sequencing with Thermusaquaticus DNA polymerase and direct sequencing of polymerase chain reaction-amplified DNA. Proc Natl Acad Sci U S A 1988, 85:9436-9440.
22. Davis AH, Wang J, Tsang TC, Harris DT: Direct sequencing is more accurate and feasible in detecting single nucleotide polymorphisms than RFLP: using human vascular endothelial growth factor gene as a model. Biol Res Nurs 2007, 9:170-178.

23. Ronaghi M, Karamohamed S, Pettersson B, Uhlén M, Nyrén P: Real-time DNA sequencing using detection of pyrophosphate release. Anal Biochem 1996, 242:84-89.

24. Dufort S, Richard MJ, Lantuejoul S, de Fraipont F: Pyrosequencing, a method approved to detect the two major EGFR mutations for anti EGFR therapy in NSCLC. J Exp Clin Cancer Res 2011, 30:57.

25. Shendure J, Mitra RD, Varma C, Church GM: Advanced sequencing technologies: methods and goals. Nat Rev Genet 2004, 5:335-344.

26. Chen YJ, Huang X: DNA sequencing by denaturation: Principle and thermodynamic simulations. Anal Biochem 2009, 384:170-179.

27. Nakamura H, Mochizuki A, Shinmyo T, Ando K, Kurimoto N, Yokote K, Takagi M: Immunohistochemical detection of mutated epidermal growth factor receptors in pulmonary adenocarcinoma. Anticancer Res 2010, 30:5233-5237.

28. Powledge TM: The polymerase chain reaction. Adv Physiol Educ 2004 28:44-50.

29. Gibbs RA: DNA amplification by the polymerase chain reaction. Anal Chem 1990, 62:1202-1214.

30. Myers TW, Gelfand DH: Reverse transcription and DNA amplification by a Thermusthermophilus DNA polymerase. Biochemistry 1991, 30:7661-7666.

31. Bustin SA: Quantification of mRNA using real-time reverse transcription PCR (RT-PCR): trends and problems. J Mol Endocrinol 2002, 29:23-39.

32. Valasek MA, Repa JJ: The power of real-time PCR. Adv Physiol Educ 2005, 29:151-159.

33. Heid CA, Stevens J, Livak KJ, Williams PM: Real time quantitative PCR. Genome Res 1996, 6:986-994.

34. Kahn SM, Jiang W, Culbertson TA, Weinstein IB, Williams GM, Tomita N, Ronai Z: Rapid and sensitive nonradioactive detection of mutant K-ras genes via 'enriched' PCR amplification. Oncogene 1991, 6:1079-1083.

35. Chen J, Viola MV: A method to detect ras point mutations in small subpopulations of cells. Anal Biochem 1991, 195:51-56.

36. Toyooka S, Tsukuda K, Ouchida M, Tanino M, Inaki Y, Kobayashi K, Yano M, Soh J, Kobatake T, Shimizu N, Shimizu K: Detection of codon 61 point mutations of the K-ras gene in lung and colorectal cancers by enriched PCR. Oncol Rep 2003, 10:1455-1459.

37. Asano H, Toyooka S, Tokumo M, Ichimura K, Aoe K, Ito S, Tsukuda K, Ouchida M, Aoe M, Katayama H, Hiraki A, Sugi K, Kiura K, Date H, Shimizu N: Detection of EGFR gene mutation in lung cancer by mutant-enriched polymerase chain reaction assay. Clin Cancer Res 2006, 12:43-48.

38. Zhang X, Zhao Y, Wang M, Yap WS, Chang AY: Detection and comparison of epidermal growth factor receptor mutations in cells and fluid of malignant pleural effusion in non-small cell lung cancer. Lung Cancer 2008, 60:175-182.

39. Kosaka $T$, Yatabe $Y$, Endoh $H$, Kuwano $H$, Takahashi $T$, Mitsudomi T: Mutations of the epidermal growth factor receptor gene in lung cancer: biological and clinical implications. Cancer Res 2004, 64:8919-8923.

40. Nagai Y, Miyazawa H, Huqun X, Tanaka T, Udagawa K, Kato M, Fukuyama S, Yokote A, Kobayashi K, Kanazawa M, Hagiwara K: Genetic heterogeneity of the epidermal growth factor receptor in non-small cell lung cancer cell lines revealed by a rapid and sensitive detection system, the peptide nucleic acid-locked nucleic acid PCR clamp. Cancer Res 2005, 65:7276-7282.

41. Sasaki H, Endo K, Konishi A, Takada M, Kawahara M, luchi K, Matsumura A, Okumura M, Tanaka H, Kawaguchi T, Shimizu T, Takeuchi H, Yano M, Fukai I, Fujii Y: EGFR Mutationstatus in Japaneselung cancerpatients: genotypinganalysis using Light Cycler. Clin Cancer Res 2005, 11:2924-2929.

42. Marchetti A, Martella C, Felicioni L, Barassi F, Salvatore S, Chella A, Camplese PP, larussi T, Mucilli F, Mezzetti A, Cuccurullo F, Sacco R, Buttitta F: EGFR mutations in non-small-cell lung cancer: analysis of a large series of cases and development of a rapid and sensitive method for diagnostic screening with potential implications on pharmacologic treatment. J Clin Oncol 2005, 23:857-865.

43. Marchetti A, Merlo G, Buttitta F, Pellegrini S, Callahan R, Bistocchi M, Squartini F: Detection of DNA mutations in acid formalin-fixed paraffin-embedded archival tumor specimens by polymerase chain reaction-single strand conformation polymorphism analysis. Cancer Detect Prev 1995, 19:278-281.

44. Qin L, Zhong W, Zhang L, Li LY, Wang MZ: Comparison of three methods for detecting epidermal growth factor receptor mutations in plasma 
DNA samples of Chinese patients with advanced non-small cell lung cancer. Chin Med J (Engl) 2011, 124:887-891.

45. Yatabe Y, Hida T, Horio Y, Kosaka T, Takahashi T, Mitsudomi T: A rapid, sensitive assay to detect EGFR mutation in small biopsy specimens from lung cancer. J Mol Diagn 2006, 8:335-341.

46. Kimura H, Kasahara K, Kawaishi M, Kunitoh H, Tamura T, Holloway B, Nishio K: Detection of epidermal growth factor receptor mutations in serum as a predictor of the response to gefitinib in patients with non-small-cell lung cancer. Clin Cancer Res 2006, 12:3915-3921.

47. Wang J, Ramakrishnan R, Tang Z, Fan W, Kluge A, Dowlati A, Jones RC, Ma PC Quantifying EGFR alterations in the lung cancer genome with nanofluidic digital PCR arrays. Clin Chem 2010, 56:623-632.

48. Maruyama K, Takeyama H, Mori T, Ohshima K, Ogura S, Mochizuki T, Matsunaga T: Detection of epidermal growth factor receptor (EGFR) mutations in non-small cell lung cancer (NSCLC) using a fully automated system with a nano-scale engineered biomagnetite. Biosens Bioelectron 2007, 22:2282-2288

49. Lee H, Kang T, Yoon KA, Lee SY, Joo SW, Lee K: Colorimetric detection of mutations in epidermal growth factor receptor using gold nanoparticle aggregation. Biosens Bioelectron 2010, 25:1669-1674.

50. Oh YH, Kim Y, Kim YP, Seo SW, Mitsudomi T, Ahn MJ, Park K, Kim HS, Mitsudomi T, Ahn MJ, Park K, Kim HS: Rapid detection of the epidermal growth factor receptor mutation in non-small-cell lung cancer for analysis of acquired resistance using molecular beacons. J Mol Diagn 2010, 12:644-652.

51. John T, Liu G, Tsao MS: Overview of molecular testing in non-small-cell lung cancer: mutational analysis, gene copy number, protein expression and other biomarkers of EGFR for the prediction of response to tyrosine kinase inhibitors. Oncogene 2009, 28:S14-S23.

52. Scagliotti GV, Selvaggi G, Novello S, Hirsch FR: The biology of epidermal growth factor receptor in lung cancer. Clin Cancer Res 2004, 10:4227s-4232s.

53. Yarden Y: The EGFR family and its ligands in human cancer: signaling mechanisms and therapeutic opportunities. Eur J Cancer 2001, 37:S3-S8.

54. Oxnard GR, Arcila ME, Sima CS, Riely GJ, Chmielecki J, Kris MG, Pao W, Ladanyi M, Miller VA: Acquired resistance to EGFR tyrosine kinase inhibitors in EGFR-mutant lung cancer: distinct natural history of patients with tumors harboring the T790M mutation. Clin Cancer Res 2011, 17:1616-1622.

55. Selvaggi G, Novello S, Torri V, Leonardo E, De Giuli P, Borasio P, Mossetti C, Ardissone F, Lausi P, Scagliotti GV: Epidermal growth factor receptor overexpression correlates with a poor prognosis in completely resected non-small-cell lung cancer. Ann Oncol 2004, 15:28-32.

56. Onn A, Correa AM, Gilcrease M, Isobe T, Massarelli E, Bucana CD, O'Reilly MS, Hong WK, Fidler IJ, Putnam JB, Herbst RS: Synchronous overexpression of epidermal growth factor receptor and HER2-neu protein is a predictor of poor outcome in patients with stage I non-small cell lung cancer Clin Cancer Res 2004, 10:136-143.

57. Herbst RS, Bunn PA Jr: Targeting the epidermal growth factor receptor in non-small cell lung cancer. Clin Cancer Res 2003, 9:5813-5824.

58. Liu W, Wu X, Zhang W, Montenegro RC, Fackenthal DL, Spitz JA, Huff LM, Innocenti F, Das S, Cook EH Jr, Cox NJ, Bates SE, Ratain MJ: Relationship of EGFR mutations, expression, amplification, and polymorphisms to epidermal growth factor receptor inhibitors in the $\mathrm{NCl} 60$ cell lines. Clin Cancer Res 2007, 13:6788-6795.

doi:10.1186/2049-6958-7-52

Cite this article as: Obradovic and Jurisic: Evaluation of current methods to detect the mutations of epidermal growth factor receptor in nonsmall cell lung cancer patients. Multidisciplinary Respiratory Medicine 2012 7:52

\section{Submit your next manuscript to BioMed Central and take full advantage of:}

- Convenient online submission

- Thorough peer review

- No space constraints or color figure charges

- Immediate publication on acceptance

- Inclusion in PubMed, CAS, Scopus and Google Scholar

- Research which is freely available for redistribution

Submit your manuscript at www.biomedcentral.com/submit
C Biomed Central 